\title{
CDX-2, MUC-2 and B-catenin as intestinal markers in pure mucinous carcinoma of the breast
}

\author{
Laura García-Labastida', Raquel Garza-Guajardo', Oralia Barboza-Quintana', Irám Pablo Rodríguez-Sanchez², \\ Jesús Ancer-Rodríguez', Juan Pablo Flores-Gutierrez and Gabriela Sofía Gómez-Macías*
}

\begin{abstract}
Background: Pure mucinous adenocarcinoma of the breast is a rare entity characterized by the production of variable amounts of mucin comprising $1 \%$ to $6 \%$ of breast carcinomas. Some mucinous adenocarcinomas have shown expression of intestinal differentiation markers such as MUC-2. This study examines the expression of intestinal differentiation markers in this type of breast carcinoma.
\end{abstract}

Results: Twenty-two cases of pure mucinous adenocarcinoma of the breast were assessed. Immunochemistry was performed for beta-catenin, CDX-2 and MUC-2. All cases were positive for B-catenin. MUC-2 positivity was observed in all cases; $63.6 \%$ were 3 plus positive. All cases were negative for CDX-2.

Conclusions: These results suggest that mucinous breast carcinomas express some markers of intestinal differentiation, such as MUC-2 and beta-catenin; however, future studies with a larger series of cases and using molecular techniques that help affirm these results are needed.

Keywords: Breast mucinous carcinoma, Inmunohistochemical, Intestinal differentiation

\section{Background}

Pure mucinous adenocarcinoma of the breast (PMACB) is a rare entity characterized by the production of variable amounts of mucin. It comprises approximately $1 \%$ to $6 \%$ of breast carcinomas $[1,2]$. Pure mucinous carcinomas are those with a mucinous component of more than $90 \%$ [3]. These tumors have a better prognosis than mixed or non-mucinous tumors $[4,5]$. Mucin synthesis is a common feature of glandular tissue and has been studied in various adenocarcinomas. Multiple studies of PMACB have shown expression of the proteins MUC1, MUC2, MUC3, MUC4, MUC5A and MUC6, and these have been postulated as prognostic factors [6,7]. The marker MUC2 is an intestinal-type mucin, which is mainly expressed in normal goblet cells of the colon and small intestine [8]. However, it is not only positive in colon cancer [9]. Its expression has also been shown in other mucinous carcinomas, which, despite their site of

\footnotetext{
* Correspondence: bpositivo66@hotmail.com

'Universidad Autónoma de Nuevo León, Hospital Universitario "Dr. José Eleuterio González", Departamento de Anatomía Patológica y Citopatología, Madero and Gonzalitos S/N, Col. Mitras Centro, Monterrey, Nuevo Leon, 64460, Mexico

Full list of author information is available at the end of the article
}

origin (salivary glands, pancreas, bladder, stomach, cervix, ovary, endometrium, and lung), share certain histological features. They are composed of glands lined with either columnar mucin producing cells with abundant extracellular mucin accumulation, or mucin-containing signet ring cells [10-12]. There are few published studies evaluating the expression of intestinal differentiation markers such as MUC2 in PMACB. Most compare their expression with usual ductal adenocarcinomas [6,7,13], and there are none that exclusively analyze more specific markers of intestinal differentiation, such as CDX-2 [14] and beta-catenin [15] in pure mucinous adenocarcinomas of the breast.

\section{Results}

During the period of 12 years there were 36 cases, of which only $22(61.1 \%)$ were considered pure mucinous in their reassessment. Thirteen cases (59\%) were associated with intraductal in situ carcinoma (DCIS). Mean age was 61 years (range 35-85) and mean tumor size was $2.49 \mathrm{~cm}$ (range 0.9-4.5 cm).

All cases were positive for beta-catenin. The most frequently observed pattern (36.4\%) was proportion 4 and strong intensity $(>75 \%$ of cells). MUC2 positivity was 


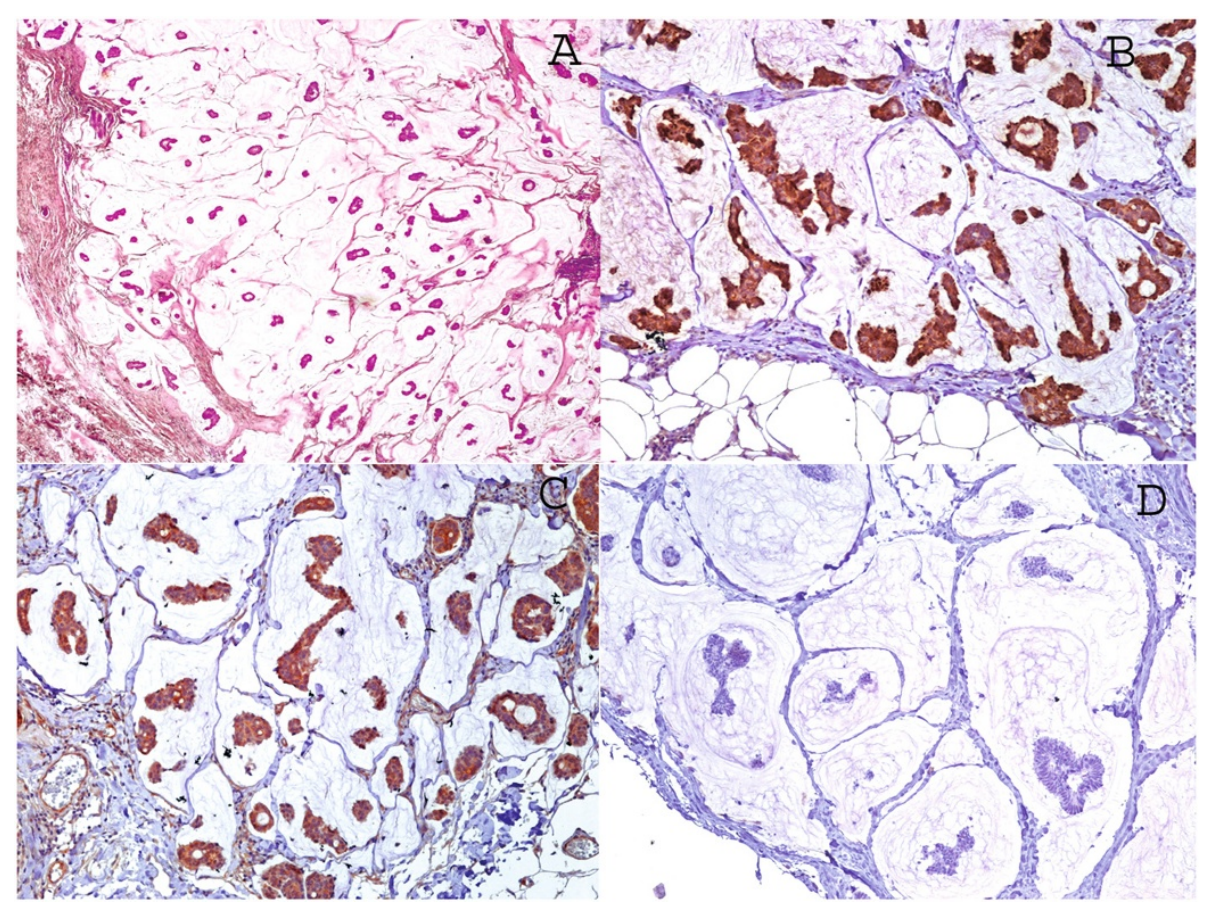

Figure 1 Mucinous type adenocarcinoma of the breast, cases without DCIS. A. A representative histopathological image H\&E 5X. Immunohistochemical stains. B. MUC2 stain. C. Beta-catenin stain. D. CDX2 stain 10x.

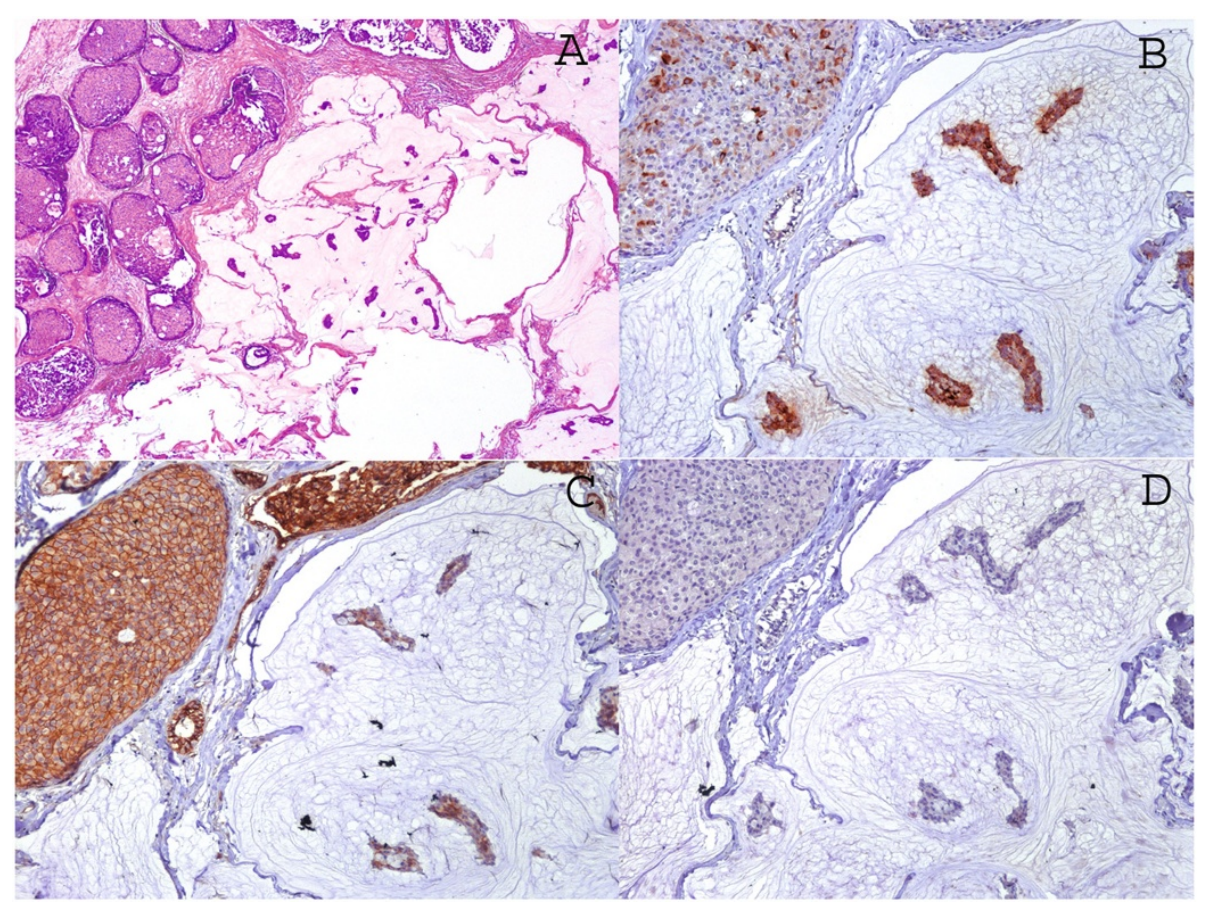

Figure 2 Mucinous type adenocarcinoma of the breast, cases associated with DCIS. A. A representative histopathological image H\&E 5X. Immunohistochemical stains. B. MUC-2 stain. C. Beta-catenin stain. We interpreted the results as proportion 1 (10-25\%) and weak intensity. D. CDX2 stain 10x 
observed in $100 \%$; $63.6 \%$ were $3+$ positive. Finally, all cases were negative for CDX-2 (Figures 1 and 2).

We compared the expression of the previously mentioned markers between those cases associated with in situ carcinoma and those without carcinoma in situ. This was done to evaluate the relationship between this histological parameter and the expression of intestinal differentiation markers. However, we found no statistically significant difference in any of the three markers (Table 1).

\section{Discussion}

Since pure mucinous adenocarcinoma of the breast (PMACB) is a variety of ductal carcinoma with specific histological features, it has attracted the interest of several authors for decades. Fujji et al. [16] demonstrated that PMACB possess a smaller number of genetic alterations in comparison with other variants of breast cancer. LacroixTriki et al. [17] found less genetic instability, suggesting that it is not only a histological entity, but also molecularly distinct from common ductal adenocarcinoma. Others studies, especially those from the late nineties, present the neuroendocrine differentiation of these neoplasms, which can occur in a variable percentage from $21 \%$ to $42 \%$ with histochemical studies, immunohistochemistry, and ultrastrcture [18-20]. The importance of this variety of breast adenocarcinoma is that numerous studies have shown that PMACB has a better prognosis than mixed or common ductal types $[4,5]$. Volkan Adsay et al. [13] propose that secretion of distinct mucin, specifically to the stromal surface, acts as a container for neoplastic cells, reducing their ability to disseminate. The findings of this study may also explain why PMACB has a better prognosis than common ductal carcinomas.

Another study demonstrated that PMACB secretes an acetylated sialomucin, which is also found in mucinous carcinomas of the colon and stomach [21]. Furthermore, immunohistochemical studies show that in PMACB, the predominant molecule is MUC2 $[6,7,13]$, which is negative in normal breast tissue. MUC2 and also, other intestinal secretory mucins $[8,9]$, have been found in other mucinous adenocarcinomas, such as those of the pancreas [22], salivary glands [23], biliary tract, the ampulla of Vater [24], the stomach [25], endometrium [26], lung [27], and ovary [28], among others.
Expression of MUC proteins in breast adenocarcinoma has been proposed as a prognostic factor. Specifically, the MUC2 marker in common ductal adenocarcinoma has been associated with less aggressive behavior, showing an inverse relationship with the presence of vascular invasion and lymph node metastasis [6,7].

Regarding beta-catenin, this is a cell adhesion molecule that plays an important role in the Wnt signaling pathway. When the Wnt beta-catenin pathway is activated, it is translocated from the cell membrane to the cytoplasm and the nucleus where it interacts with genes that activate transcription factors [29]. Many studies have demonstrated activation of this pathway in adenocarcinoma of the breast $[30,31]$. Also, it plays an important role in colorectal carcinogenesis, activating the APC gene pathway or the Wnt signaling pathway [10]. In cases of colorectal carcinoma, 90\% show nuclear positivity for beta-catenin [32]. Although both adenocarcinomas share this molecular pathway, we could not find any case of pure mucinous adenocarcinoma of the breast that displays a nuclear staining pattern similar to that of colon adenocarcinoma. This agrees with the work by Peiguo Chu et al., who tried to determine the site of origin of 175 cases of mucinous adenocarcinoma. The authors included 18 cases that were found to be primary breast tumors and none showed nuclear positivity for beta-catenin [10]. Regardless of this, the majority of studies of beta-catenin expression in adenocarcinoma of the breast have tried to correlate its expression with clinical behavior. Decreased expression or aberrant expression has been associated with increased frequency of positive lymph node metastasis, and overexpression of the HER2 neu and basal phenotype [30,31].

On the other hand, CDX2 is a gene belonging to the homeobox gene family, which is required for intestinal organogenesis and encoding nuclear transcription factors involved in the proliferation and differentiation of intestinal epithelium. The highest frequency of CDX2 staining occurred in colorectal carcinomas when compared with tumors from other sites. Therefore, the high frequency of CDX2 staining in colorectal adenocarcinomas, staining in extraintestinal tumors with intestinaltype epithelium, and uncommon staining in tumors from various sites lacking an intestinal phenotype sugg4ests that it is a useful marker for intestinal-type differentiation $[14,33]$. O'Connell et al. [34] conducted a

Table 1 Comparison of expression of intestinal differentiation and the association with in situ carcinoma (DCIS)

\begin{tabular}{llll}
\hline Marker & Without DCIS $(\mathbf{n}=\mathbf{1 3})$ & With DCIS(n= 9) & $\boldsymbol{P}$ \\
\hline Intestinal differentiation markers, $\mathbf{n}(\%)$ & & & $9(100)$ \\
Beta-catenin & $13(100)$ & $9(100)$ & .251 \\
MUC 2 & $13(100)$ & 0 & .298 \\
CDX-2 & 0 & Not applicable*
\end{tabular}

*No statistical value since all cases were negative. 
Table 2 Intestinal differentiation markers and parameters used to evaluate positivity

\begin{tabular}{|c|c|c|c|c|c|}
\hline Marker & Mark & Dilution & Positivity & Proportion & Intensity \\
\hline \multirow[t]{4}{*}{ MUC 2} & Cell Marque MRQ-18 & Prediluted & Luminar/Cytoplasmic Cytoplasmic/membranous & $>5 \%$ of neoplastic cells & $0=$ Negative \\
\hline & & & & & $1=$ weak \\
\hline & & & & & $2=$ moderate \\
\hline & & & & & $3=$ strong \\
\hline \multirow[t]{3}{*}{$\operatorname{CD} \times 2$} & Biocare Medical CDX2-88 & 1: 50 & Nuclear & $25 \%=1+$ & $1+=$ weak \\
\hline & & & & $26-75 \%=2+$ & $2+=$ strong \\
\hline & & & & $>75 \%=3+$ & \\
\hline \multirow[t]{5}{*}{ B-catenin } & Santa Cruz E-5 & 1: 50 & Membranous & $0=0-10 \%$ & $0=$ Negative \\
\hline & & & & $1=10-25 \%$ & $1=$ weak \\
\hline & & & & $2=25-50 \%$ & $2=$ moderate \\
\hline & & & & $3=50-75 \%$ & $3=$ strong \\
\hline & & & & $4=>75 \%$ & \\
\hline
\end{tabular}

study of the role of immunohistochemistry in distinguishing primary adenocarcinomas of the gastrointestinal tract versus metastatic breast cancers, in which 47 adenocarcinomas involving the gastrointestinal tract were examined, including 19 cases of primary breast cancer. In their results, $100 \%$ of the cases from breast were negative for CDX-2. The results of our work and that of O'Connell are consistent with other studies in which, despite constant expression of MUC 2 in PMACB, no case showed positivity for CDX-2 [10]. However, among colorectal adenocarcinomas, the relationship between tumor grade and CDX2 staining has been controversial. CDX2 does not appear to be a sensitive marker for poorly differentiated colorectal carcinomas, and it is not a completely specific marker. Finally, CDX2 also stains other non-intestinal mucinous tumors, most notably carcinomas of lung, ovary and endometrium [14]. This can be a 'pitfall' in assessing primary site or of a metastatic mucinous tumor of unknown origin, especially if it is poorly differentiated.

Although expression of these markers in other studies has been associated with prognosis and other histological parameters, we found no statistically significant differences between those cases with and without DCIS.

\section{Conclusions}

In conclusion the results of this study suggest that mucinous breast carcinomas express some markers of intestinal differentiation; however, future studies containing a larger series and other molecular techniques that help affirm the results of this study are required.

\section{Methods}

We performed a retrospective observational review of pathological reports of patients with mucinous type adenocarcinomas of the breast obtained from the Pathology and Cytopathology Department of the UANL
University Hospital in Monterrey, Mexico in a period of 12 years (January 2000 to December 2011). We included only cases with at least $90 \%$ mucinous differentiation. We excluded those cases that did not have a paraffin block. All cases were reevaluated with the usual technique of hematoxylin and eosin, in 3 micron slices. The most representative slice of each tumor was selected and immunohistochemical staining was performed for betacatenin, CDX-2 and MUC2. The immunohistochemical technique applied was based on the manufacturer's recommendations for each antibody. The antibodies, company, dilutions and criteria used to evaluate positivity are summarized in Table 2. These were based on previous studies with the markers $[6,10,29]$. We included positive and negative controls for each marker on each slide. For statistical analysis, we used SPSS version 17.

\section{Abbreviations}

PMACB: Pure mucinous adenocarcinoma of the breast; ER: Estrogen receptor; PR: Progesterone receptor.

\section{Competing interests}

The authors declare that they have no competing interests.

\section{Authors' contributions}

LGL wrote the main paper. IPRS carried out the revision of the literature. $\mathrm{OBQ}$ participated in the sequence alignment and drafted the manuscript. RGG provided the images. JPFG conducted immunohistochemical stains and participated in their interpretation. JAR supervised the project. GSGM conceived of the study, and participated in its design and coordination and helped to draft the manuscript. All authors read and approved the final manuscript.

\section{Acknowledgments}

We thank Sergio Lozano-Rodríguez, M.D. for his help in translating the text and Jose Segura-Luna for statistical analysis.

\section{Funding}

The work was performed using resources provided by each of the participating departments.

\section{Author details}

${ }^{1}$ Universidad Autónoma de Nuevo León, Hospital Universitario “Dr. José Eleuterio González", Departamento de Anatomía Patológica y Citopatología, 
Madero and Gonzalitos S/N, Col. Mitras Centro, Monterrey, Nuevo Leon, 64460, Mexico. ${ }^{2}$ Universidad Autónoma de Nuevo León, Hospital Universitario "Dr. José Eleuterio González", Departamento de Genética, Av. Madero and Gonzalitos S/N, Col. Mitras Centro, Monterrey, Nuevo León 64460, Mexico

Received: 14 March 2014 Accepted: 28 July 2014

Published: 18 September 2014

\section{References}

1. Bae SY, Choi MY, Cho DH, Lee JE, Nam SJ, Yang JH: Mucinous Carcinoma of the Breast in Comparison with Invasive Ductal Carcinoma: Clinicopathologic Characteristics and Prognosis. J Breast Cancer 2011, 14:308-313.

2. Bal A, Joshi K, Sharma SC, Das A, Verma A, Wig JD: Prognostic Significance of Micropapillary Pattern in Pure Mucinous Carcinoma of the Breast. Int J Surg Pathol 2008, 16:251-256.

3. Komaki K, Sakamoto G, Sugano H, Morimoto T, Monden Y: Mucinous carcinoma of the breast in Japan. A prognostic analysis based on morphologic features. Cancer 1988, 61:989-996.

4. Di Saverio S, Gutierrez J, Avisar E: A retrospective review with long term follow up of 11,400 cases of pure mucinous breast carcinoma. Breast Cancer Res Treat 2008, 111:541-547.

5. Barkley CR, Ligibel JA, Wong JS, Lipsitz S, Smith BL, Golshan M: Mucinous breast carcinoma: a large contemporary series. Am J Surg 2008, 196:549-51.

6. Rakha EA, Boyce RW, Abd El-Rehim D, Kurien T, Green AR, Paish EC, Robertson JF, Ellis IO: Expression of mucins (MUC1, MUC2, MUC3, MUC4, MUC5AC and MUC6) and their prognostic significance in human breast cancer. Mod Pathol 2005, 18:1295-1304.

7. Matsukita S, Nomoto M, Kitajima S, Tanaka S, Goto M, Irimura T, Kim YS, Sato E, Yonezawa S: Expression of mucins (MUC1, MUC2, MUC5AC and MUC6) in mucinous carcinoma of the breast: comparison with invasive ductal carcinoma. Histopathology 2003, 42:26-36.

8. Mcintire MG, Soucy G, Vaughan TL, Shahsafaei A, Odze RD: MUC2 Is a Highly Specific Marker of Goblet Cell Metaplasia in the Distal Esophagus and Gastroesophageal Junction. Am J Surg Pathol 2011, 35:1007-1013.

9. Li A, Goto M, Horinouchi M, Tanaka S, Imai K, Kim YS, Sato E, Yonezawa S: Expression of MUC1 and MUC2 mucins and relationship with cell proliferative activity in human colorectal neoplasia. Pathol Int 2011, 51:853-860.

10. Chu PG, Chung L, Weiss LM, Lau SK: Determining the site of origin of mucinous adenocarcinoma: an immunohistochemical study of 175 cases. Am J Surg Pathol 2011, 35:1830-1836.

11. Hanski C, Hofmeier M, Schmitt-Gräff A, Riede E, Hanski ML, Borchard F, Sieber E, Niedobitek F, Foss HD, Stein H, Riecken EO: Overexpression or ectopic expression of MUC2 is the common property of mucinous carcinomas of the colon, pancreas, breast, and ovary. J Pathol 1997, 182:385-391.

12. Lau SK, Weiss LM, Chu PG: Differential expression of MUC1, MUC2, and MUC5AC in carcinomas of various sites: an immunohistochemical study. Am J Clin Pathol 2004, 122:61-69.

13. Adsay NV, Merati K, Nassar H, Shia J, Sarkar F, Pierson CR, Cheng JD, Visscher DW, Hruban RH, Klimstra DS: Pathogenesis of colloid (pure mucinous) carcinoma of exocrine organs: Coupling of gel-forming mucin (MUC2) production with altered cell polarity and abnormal cell-stroma interaction may be the key factor in the morphogenesis and indolent behavior of colloid carcinoma in the breast and pancreas. Am J Surg Pathol 2003, 27:571-578.

14. De Lott LB, Morrison C, Suster S, Cohn DE, Frankel WL: CDX2 is a useful marker of intestinal-type differentiation: a tissue microarray-based study of 629 tumors from various sites. Arch Pathol Lab Med 2005, 129:1100-1105.

15. Ikeda S, Shimizu Y, Fujimori M, Ishizaki Y, Kurihara T, Ojima Y, Okajima M, Asahara T: Immunohistochemical and mutational analyses of beta-catenin, $\mathrm{K}$-ras, and $\mathrm{p} 53$ in two subtypes of colorectal mucinous carcinoma. Clin Cancer Res 2003, 9:5660-5665.

16. Fujii H, Anbazhagan R, Bornman DM, Garrett ES, Perlman E, Gabrielson E: Mucinous cancers have fewer genomic alterations than more common classes of breast cancer. Breast. Cancer Res Treat 2002, 76:255-260.

17. Lacroix-Triki M, Suarez PH, Mackay A, Lambros MB, Natrajan R, Savage K, Geyer FC, Weigelt B, Ashworth A, Reis-Filho JS: Mucinous carcinoma of the breast is genomically distinct from invasive ductal carcinomas of no special type. J Pathol 2010, 222:282-298.
18. Kato N, Endo $\mathrm{Y}$, Tamura G, Katayama Y, Motoyama T: Mucinous carcinoma of the breast: a multifaceted study with special reference to histogenesis and neuroendocrine differentiation. Pathol Int 1999, 49:947-955.

19. Weigelt B, Geyer FC, Horlings HM, Kreike B, Halfwerk H, Reis-Filho JS: Mucinous and neuroendocrine breast carcinomas are transcriptionally distinct from invasive ductal carcinomas of no special type. Mod Pathol 2009, 22:1401-1414.

20. Scopsi L, Andreola S, Pilotti S, Bufalino R, Baldini MT, Testori A, Rilke F: Mucinous carcinoma of the breast. A clinicopathologic, histochemical, and immunocytochemical study with special reference to neuroendocrine differentiation. Am J Surg Pathol 1994, 18:702-711.

21. Sáez C, Japón MA, Poveda MA, Segura DI: Mucinous (colloid) adenocarcinomas secrete distinct O-acylated forms of sialomucins: a histochemical study of gastric, colorectal and breast adenocarcinomas. Histopathology 2001, 39:554-560

22. Liszka L, Zielinska-Pajak E, Pajak J, Gołka D: Colloid carcinoma of the pancreas: review of selected pathological and clinical aspects. Pathology 2008, 40:655-563.

23. Alos L, Lujan B, Castillo M, Nadal A, Carreras M, Caballero M, DE Bolos C, Cardesa A: Expression of membrane-bound mucins (MUC1 and MUC4) and secreted mucins (MUC2, MUC5AC, MUC5B, MUC6 and MUC7) in mucoepidermoid carcinomas of salivary glands. Am J Surg Pathol 2005, 29:806-813

24. Chu PG, Schwarz RE, Lau SK, Yen Y, Weiss LM: Immunohistochemical staining in the diagnosis of pancreatobiliary and ampulla of Vater adenocarcinoma: application of CDX2, CK17, MUC1, and MUC2. Am J Surg Pathol 2005, 29:359-367.

25. Pinto-De-Sousa J, David L, Reis CA, Gomes R, Silva L, Pimenta A: Mucins MUC1, MUC2, MUC5AC and MUC6 expression in the evaluation of differentiation and clinico-biological behaviour of gastric carcinoma. Virchows Arch 2002, 440:304-310.

26. Alameda F, Mejías-Luque R, Garrido M, De Bolós C: Mucin genes (MUC2, MUC4, MUC5AC, and MUC6) detection in normal and pathological endometrial tissues. Int J Gynecol Pathol 2007, 26:61-65.

27. Rossi G, Murer B, Cavazza A, Losi L, Natali P, Marchioni A, Migaldi M, Capitanio G, Brambilla E: Primary mucinous (so-called colloid) carcinomas of the lung: a clinicopathologic and immunohistochemical study with special reference to CDX-2 homeobox gene and MUC2 expression. Am J Surg Pathol 2004, 28:442-452.

28. Hirabayashi K, Yasuda M, Kajiwara H, Itoh J, Miyazawa M, Hirasawa T, Muramatsu T, Murakami M, Mikami M, Osamura RY: Alterations in mucin expression in ovarian mucinous tumors: immunohistochemical analysis of MUC2, MUC5AC, MUC6, and CD10 expression. Acta Histochem Cytochem 2008, 41:15-21.

29. Geyer FC, Lacroix-Triki M, Savage K, Arnedos M, Lambros MB, Mackay A, Natrajan R, Reis-Filho JS: $\beta$-Catenin pathway activation in breast cancer is associated with triple-negative phenotype but not with CTNNB1 mutation. Mod Pathol 2011, 24:209-231.

30. Zhang YG, Du J, Tian XX, Zhong YF, Fang WG: Expression of E-cadherin, beta-catenin, cathepsin $D$, gelatinases and their inhibitors in invasive ductal breast carcinomas. Chin Med J 2007, 120:1597-1605.

31. Dolled-Filhart M, Mccabe A, Giltnane J, Cregger M, Camp RL, Rimm DL: Quantitative in situ analysis of beta-catenin expression in breast cancer shows decreased expression is associated with poor outcome. Cancer Res 2006, 66:5487-5494.

32. Wong NA, Pignatelli M: Beta-catenin-a linchpin in colorectal carcinogenesis? Am J Pathol 2002, 160:389-401.

33. Raspollini MR, Amunni G, Villanucci A, Baroni G, Taddei A, Taddei GL: Utility of CDX-2 in distinguishing between primary and secondary (intestinal) mucinous ovarian carcinoma: an immunohistochemical comparison of 43 cases. Appl Immunohistochem Mol Morphol 2004, 12:127-131.

34. O'Connell FP, Wang HH, Odze RD: Utility of immunohistochemistry in distinguishing primary adenocarcinomas from metastatic breast carcinomas in the gastrointestinal tract. Arch Pathol Lab Med 2005, 129:338-347.

doi:10.1186/0717-6287-47-43

Cite this article as: García-Labastida et al:: CDX-2, MUC-2 and B-catenin as intestinal markers in pure mucinous carcinoma of the breast. Biological Research 2014 47:43. 